Ji Zhikang, Yu Sirong* and Yin Xiaoli

\title{
Degradable Mg alloy composites using fly ash cenospheres
}

https://doi.org/10.1515/secm-2017-0243

Received July 18, 2017; accepted October 21, 2017; previously published online December 4, 2017

\begin{abstract}
The feasibility of fabricating Mg alloy degradable composites with fly ash cenospheres (FACs) using stir casting has been demonstrated. The effects of FAC addition (mass fraction: 0, 2, 4, 6, 8 and $10 \mathrm{wt} . \%$ ) on the microstructure, mechanical properties and corrosion behavior were investigated using optical microscope, scanning electron microscope, X-ray diffraction, density tests, compression tests, immersion tests and electrochemical measurements. The result shows that the degradable composites are mainly composed of $\alpha-\mathrm{Mg}, \beta-\mathrm{Mg}_{17} \mathrm{Al}_{12}$, $\mathrm{Mg}_{2} \mathrm{Si}$ and $\mathrm{MgO}$ phase, and FAC can refine the grain size. The average measured densities of the FAC/Mg alloy composites are higher than the theoretical values due to the formation of the $\mathrm{Mg}_{2} \mathrm{Si}$ phase, which are in the range of 1.8843-2.0526 g/ $\mathrm{cm}^{3}$. The compressive strength of the degradable composites dramatically enhances with the addition of FAC, and the maximum strength is $375 \mathrm{MPa}$ with the 8 -wt.\% mass fraction, which can be attributed to the refined grains and the formation of massive $\mathrm{Mg}_{2} \mathrm{Si}$ phase. Furthermore, the corrosion rate of the degradable composites with 10 wt.\% FACs shows the highest value of $5.02 \mathrm{~g} / \mathrm{h}$ in $3 \mathrm{wt} . \%$ potassium chloride solution at $80^{\circ} \mathrm{C}$, which is three times higher than the corrosion rate of composites without FAC. With the increase in FAC content, more $\mathrm{Mg}_{2} \mathrm{Si}$ phases formed; thus, micro-galvanic corrosion works well in the composites.
\end{abstract}

Keywords: corrosion behavior; degradable composites; fly ash cenospheres; mechanical properties.

\section{Introduction}

As the world economy develops, the consumption of oil and gas puts enormous pressure on society. Accordingly,

*Corresponding author: Yu Sirong, College of Mechanical and Electronic Engineering, China University of Petroleum (East China), Qingdao, 266580, P. R. China, e-mail: yusr@upc.edu.cn Ji Zhikang and Yin Xiaoli: College of Mechanical and Electronic Engineering, China University of Petroleum (East China), Qingdao, 266580, P. R. China the utmost degree of increased oil recovery has become the common goal of the petroleum industry. In recent years, the multi-stage fracturing technique with ball and sliding sleeve used in unconventional oil and gas production has developed considerably. The technology can be used in both horizontal and vertical wells, which is more helpful in improving production efficiency and reducing production risks [1-3]. One of the key tools in the multi-stage fracturing technique is the fracturing ball, which must have enough strength to bear the erosion wear and high pressure in the practical down-hole working environment [4, 5]. Conventionally, the fracturing balls need to be eliminated by milling or drilling when the fracturing process is accomplished, which is generally a complicated and very costly process $[6,7]$. Thus, the ball material should also have low density. Zhang et al. [8] reported that a fracturing ball made of polyarylether ketone can be corroded in a few days in 3 wt.\% potassium chloride ( $\mathrm{KCl})$; however, the material has low compressive strength $(100 \mathrm{MPa})$. Carrejo et al. [9] conducted a study on metallic composite, called high-strength corrodible material, which demonstrated excellent compressive strength and corrodible rate. Several studies showed that stainless steel, TORLON and aluminum alloys are unsuitable for fabricating fracturing balls due to their extremely high density and poor degradability (high corrosion resistance) [1-3, 6, 7].

$\mathrm{Mg}$ matrix composites have seen considerable development especially for automobile and aircraft applications owing to their low density, high specific strength and stiffness, excellent machinability and poor corrosion resistance [10-12]. Fracturing ball fabricated with $\mathrm{Mg}$ alloy needs a rapid degradation rate, which not only utilizes the advantages of $\mathrm{Mg}$ alloy, such as low density and high specific strength, but also employs the shortcoming of $\mathrm{Mg}$ alloy, which is easy corrosion. Recently, $\mathrm{Mg}$ matrix composites reinforced with in situ particles like $\mathrm{SiC}_{\mathrm{p}}, \mathrm{SiO}_{2}$, $\mathrm{Al}_{2} \mathrm{O}_{3}$ etc. have made great progress [13-16]. However, its application has many restrictions due to the addition of expensive reinforcements [17].

Fly ash cenospheres (FACs) are coal-fired products of thermal power stations. Large amounts FAC emissions into the atmosphere will seriously pollute the environment. FACs made of $\mathrm{SiO}_{2}, \mathrm{Al}_{2} \mathrm{O}_{3}, \mathrm{Fe}_{2} \mathrm{O}_{3}$, etc. are hollow, with an average density of about $0.4-0.6 \mathrm{~g} / \mathrm{cm}^{3}$ and diameter of 0.5-320 $\mu \mathrm{m}$. FACs have high elastic modulus. Substantial 
progress has been demonstrated by FACs, which, when combined with metallic or concrete matrix, can be used as reinforcement in the production of composite foams with excellent properties and low density $[18,19]$. Over the last two decades, automotive components and machine parts have been fabricated by fly ash-reinforced metal matrix composites [20]. Using FACs in Mg alloys is advantageous not only because of their low cost and excellent physical and mechanical properties, but the application of FACs in composites also utilizes industrial garbage and thus protects the environment.

However, currently, only few literatures can be found on the preparation of $\mathrm{Mg}$ matrix degradable composites that incorporates FAC. Therefore, the main objective of the paper is to fabricate FAC/Mg alloy degradable composites using the stir casting method. Accordingly, the effects of FAC addition on the microstructure, mechanical properties and corrosion behavior are investigated.

\section{Materials and methods}

\subsection{Materials}

The chemical composition of the matrix of FAC/Mg alloy degradable composites is given as follows: $\mathrm{Al}, 12 \mathrm{wt} . \%$; $\mathrm{Zn}$, 3 wt.\%; Cu, 0.5 wt.\%; Ni, 1 wt.\%; Mg, balance. The various weight percentages of FAC addition are given in Table 1. Commercial AZ91D Mg alloy, pure Al ingot (99.6 wt.\%), pure Zn powder (95.0 wt.\%), pure Cu powder (99.7 wt.\%), pure Ni powder (99.7 wt.\%) and FAC were used as raw materials to fabricate the $\mathrm{FAC} / \mathrm{Mg}$ alloy degradable composites. Tables 2 and 3 show the chemical compositions

Table 1: FAC addition of the composites (wt.\%).

\begin{tabular}{lrrrrrr}
\hline Sample & Alloy 1 & Alloy 2 & Alloy 3 & Alloy 4 & Alloy 5 & Alloy 6 \\
\hline FAC & 0 & 2 & 4 & 6 & 8 & 10 \\
\hline
\end{tabular}

Table 2: Chemical composition of FACs (wt.\%).

\begin{tabular}{lllllll}
\hline $\mathrm{SiO}_{2}$ & $\mathrm{Al}_{2} \mathrm{O}_{3}$ & $\mathrm{Fe}_{2} \mathrm{O}_{3}$ & $\mathrm{CaO}$ & $\mathrm{MgO}$ & $\mathrm{K}_{2} \mathrm{O}$ & Others \\
\hline 55.00 & 38.90 & 4.27 & 0.40 & 0.73 & 0.74 & Bal. \\
\hline
\end{tabular}

Table 3: Chemical composition of AZ91D Mg alloy (wt.\%).

\begin{tabular}{lrrrrr}
\hline Al & Zn & Mn & Si & Cu & Mg \\
\hline 9.07 & 0.62 & 0.21 & 0.034 & 0.003 & Bal. \\
\hline
\end{tabular}

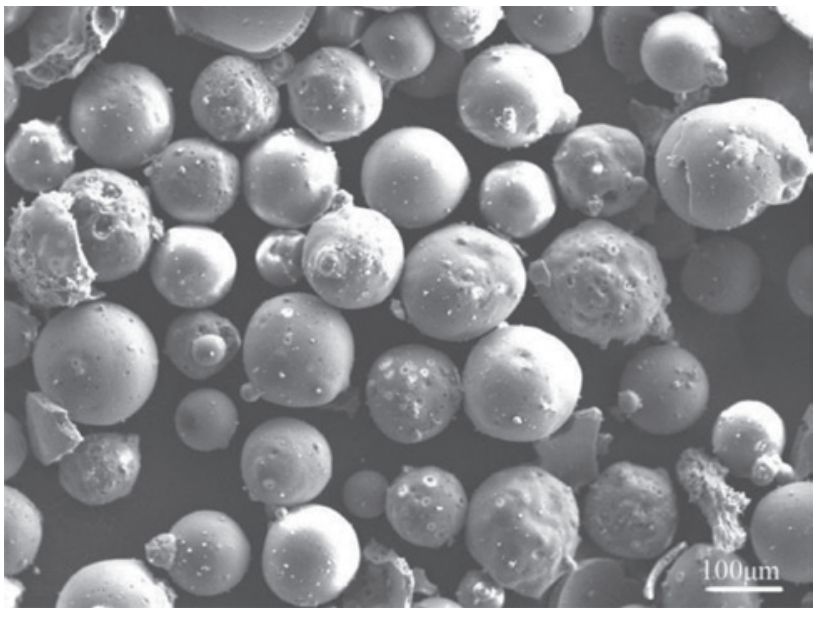

Figure 1: SEM microstructure showing the morphology of FAC particles.

of FAC and AZ91D Mg alloy used in the synthesis of the composites, respectively. The morphology of FAC, whose average diameter is about $148 \mu \mathrm{m}$, is shown in Figure 1.

\subsection{Sample preparation}

The Mg alloy was melted in a mild steel crucible in an electric resistance furnace to $720^{\circ} \mathrm{C}$, and then cooled to $590^{\circ} \mathrm{C}$ and slagged off. Then, the melt was stirred at a rotation speed of $43 \mathrm{~g}$; at the same time, FACs were added to the melt, and the slurry was continuously stirred for 3 min to ensure that the FACs were fully incorporated and uniformly dispersed in the melt. Then, the melt was reheated to $720^{\circ} \mathrm{C}$ and poured into a graphite crucible preheated to $150^{\circ} \mathrm{C}$, producing castings $28 \mathrm{~mm}$ in diameter and $110 \mathrm{~mm}$ in length. The mixed 3 vol. $\% \mathrm{SF}_{6}$ and $\mathrm{CO}_{2}$ gas were used to avoid the oxidation and combustion of the Mg alloy during all processes.

\subsection{Characterization of the microstructure and properties}

The microstructure and phase constitutions were analyzed using optical microscopy (Leica DM2500-M, Leica Microsystems, Mannheim, Germany), scanning electron microscope (SEM; S-3400, Hitachi, Japan) and X-ray diffraction (XRD, D/MAX-2000PC, Rigaku, Japan). All samples for the observation of the microstructure were cut from the middle of the composite casting. A universal material test machine (WDW-300, Bairoe, Shanghai, China) was used for the compression testing at a constant rate of $2 \mathrm{~mm} / \mathrm{min}$, and the specimens were $10 \mathrm{~mm}$ in diameter and 
$20 \mathrm{~mm}$ in length. The density of the degradable composites was measured based on the Archimedes principle using a microbalance (Mettler Toledo, Shanghai, China) capable of measuring weight with a precision of $0.0001 \mathrm{~g}$. In these two types of experiments, samples in triplicate are used.

The corrosion behavior of the FAC/Mg alloy degradable composites was investigated using immersion test and polarization curve measurements. The specimens were all cylindrical with $28 \mathrm{~mm}$ in diameter and $20 \mathrm{~mm}$ in length, which were cut from the same location of the casting by electrical discharge machining. The immersion tests were carried out in 3 wt.\% KCl (Sinopharm Chemical Reagent Co., Ltd, Shanghai, China) solution at three temperatures $\left(25,50\right.$ and $\left.80^{\circ} \mathrm{C}\right)$ and four times $(3,6,12$ and $15 \mathrm{~h})$. After immersion test, the specimens were cleaned for $3 \mathrm{~min}$ in the mixed solution of $\mathrm{CrO}_{3}$ (Sinopharm Chemical Reagent Co., Ltd, Shanghai, China) $(180 \mathrm{~g} / \mathrm{L})$ and $\mathrm{AgNO}_{3}$ (Sinopharm Chemical Reagent Co., Ltd, Shanghai, China) $(10 \mathrm{~g} / \mathrm{L})$ to remove the corrosion products. Finally, the specimens were ultrasonically cleaned in distilled water and dried in a dry-box for 10 minutes. The immersion tests are conducted three times to ensure repeatability, according to ASTM G31-2012a [21]. The average corrosion rates were calculated using the following equation:

$$
V=\frac{M_{0}-M_{\mathrm{t}}}{t}
$$

where $M_{0}$ is the initial weight (mg), $M_{\mathrm{t}}$ is the weight $(\mathrm{mg})$ after the corrosion treatments for $t$ hours and $t$ is the immersion time (h). The electrochemical measurements were conducted in CS350 electrochemical test equipment (Wuhan Corrtest Instruments Corp., Ltd, Wuhan, China) using a saturated calomel electrode as reference electrode, a platinum electrode as counter-electrode and the composite specimens as working electrode with a surface of about $10 \mathrm{~mm}$ in diameter. Polarization curves were measured at $25^{\circ} \mathrm{C}$ in $3 \mathrm{wt} . \% \mathrm{KCl}$ solution with the scanning rate of $1 \mathrm{mV} / \mathrm{s}$.

\section{Results and discussion}

\subsection{Microstructures}

The XRD patterns (Figure 2) suggest that alloy 1 (base $\mathrm{Mg}$ alloy) consisted of $\alpha-\mathrm{Mg}$ and $\beta-\mathrm{Mg}_{17} \mathrm{Al}_{12}$ phases, whereas the main phases in alloy 4 ( $6 \mathrm{wt} . \%$ FAC addition) are $\alpha-\mathrm{Mg}$, $\beta-\mathrm{Mg}_{17} \mathrm{Al}_{12}, \mathrm{Mg}_{2} \mathrm{Si}$ and $\mathrm{MgO}$. Figure 3 shows the microstructures of the base $\mathrm{Mg}$ alloy and the FAC/Mg alloy degradable composites with mass fraction of $2 \%, 4 \%, 6 \%, 8 \%$ and

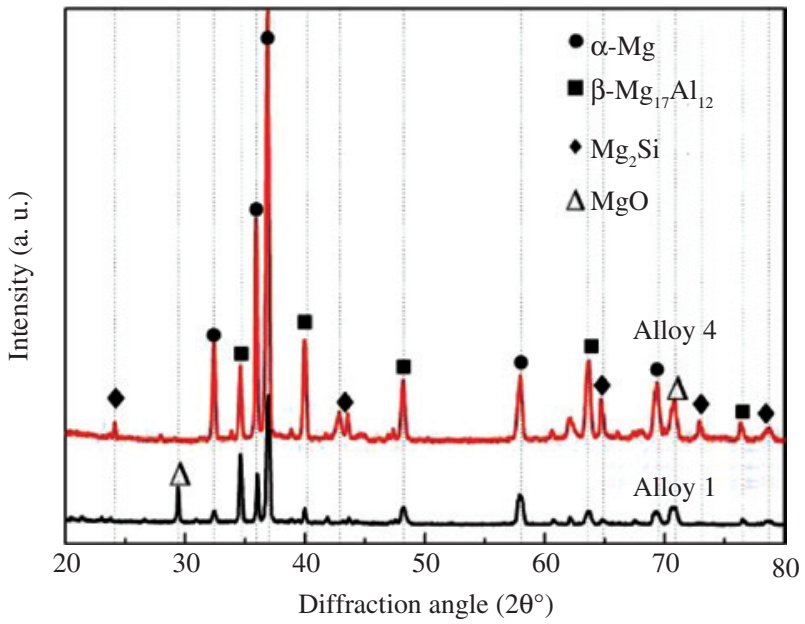

Figure 2: XRD patterns of the base Mg alloy (alloy 1) and FAC/Mg alloy degradable composites (alloy 4).

$10 \%$, respectively. The FACs were practically entirely filled with the Mg matrix. There are some FACs fractured and concentrating porosities on their walls. The microstructure of the composites is refined compared with the base $\mathrm{Mg}$ alloy without FAC particle addition. This is because the added FACs change the solidification mode of the $\mathrm{Mg}$ alloy. In the cooling process, the wall of FACs can be used as substrate for the crystal nucleus, which reduces the nucleation energy. Thus, more crystals can form, and the grain is refined. The polygonal $\mathrm{Mg}_{2} \mathrm{Si}$ particles are detected, which resulted from the reaction between the FACs and the molten $\mathrm{Mg}$ alloy, and the amount of $\mathrm{Mg}_{2} \mathrm{Si}$ particles increases linearly with FAC content. The following reactions should occur based on thermodynamic calculation [22]:

$$
\begin{aligned}
& 4 \mathrm{Mg}(\mathrm{l})+\mathrm{SiO}_{2}(\mathrm{~s})=\mathrm{Mg}_{2} \mathrm{Si}(\mathrm{s})+2 \mathrm{MgO}(\mathrm{s}), \\
& \Delta G_{1}=-412.4 \mathrm{~kJ} / \mathrm{mol} \\
& 3 \mathrm{Mg}(\mathrm{l})+\mathrm{Al}_{2} \mathrm{O}_{3}(\mathrm{~s})=2 \mathrm{Al}(\mathrm{l})+3 \mathrm{MgO}(\mathrm{s}), \\
& \Delta G_{2}=-118.5 \mathrm{~kJ} / \mathrm{mol}
\end{aligned}
$$

\subsection{Physical properties}

Figure 4 shows the measured density values of the FAC $/ \mathrm{Mg}$ alloy degradable composites in comparison to the theoretical values calculated (using the rule of mixtures) for the composites versus the mass fraction of the FAC particles. Lines II and III in Figure 4 show the theoretical density values of the composites with filled and unfilled FAC by Mg matrix, respectively. In this calculation, the density values of the FAC walls and the hollow FAC are assumed to 

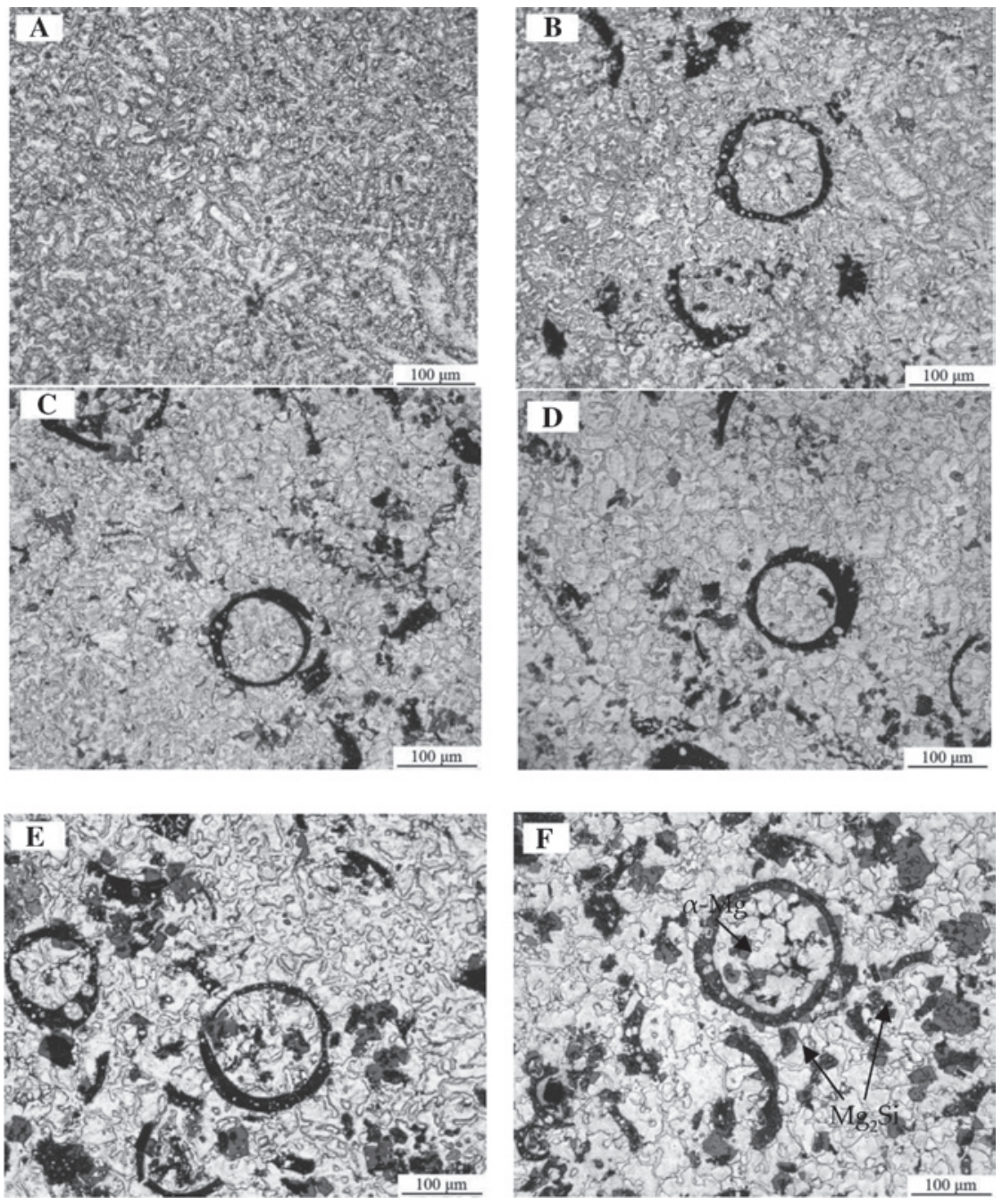

Figure 3: Microstructures of the base Mg alloy (A, alloy 1) and FAC/Mg alloy degradable composites (B, alloy 2; C, alloy 3; D, alloy 4; E, alloy 5 ; F, alloy 6).

I: Measured density of degradable composites O II: Theoretical density-FAC filled by magnesium matrix

A III: Theoretical density-FAC unfilled by magnesium matrix

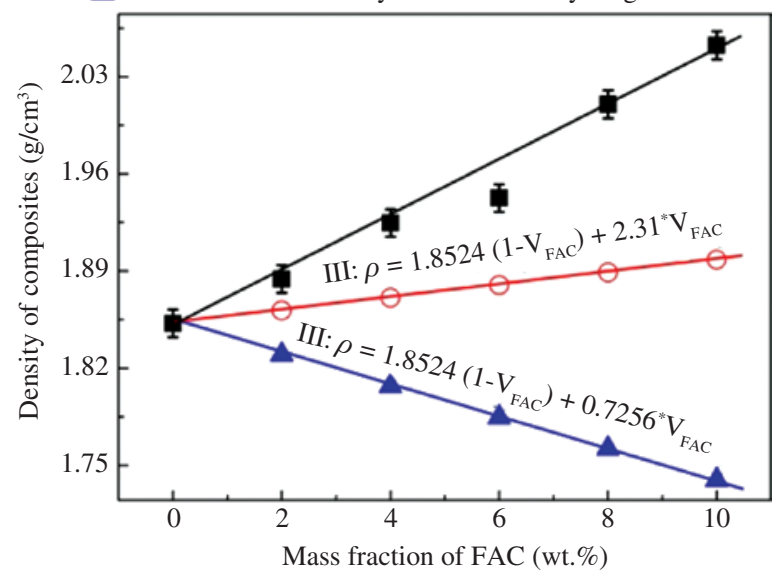

Figure 4: Theoretical and measured density values of the composites versus FAC mass fraction. be 2.31 and $0.7256 \mathrm{~g} / \mathrm{cm}^{3}$, respectively. The obtained measured density values are still above the theoretical density values for the composites because the FAC are completely filled with $\mathrm{Mg}$ matrix. On the other hand, by adding FAC, an increasing amount of polygonal $\mathrm{Mg}_{2} \mathrm{Si}$ (density=1.99 $\mathrm{g} / \mathrm{cm}^{3}$ [23]) is dramatically generated, which is due to the reaction between the FAC and the Mg matrix. The measured average density values of the $\mathrm{FAC} / \mathrm{Mg}$ alloy degradable composites are from 1.8843 to $2.0526 \mathrm{~g} / \mathrm{cm}^{3}$.

\subsection{Mechanical properties}

Figure 5 shows the compressive stress-strain curves of the base $\mathrm{Mg}$ alloy and $\mathrm{FAC} / \mathrm{Mg}$ alloy degradable composites at room temperature. As can be seen, the curve is composed of an elastic region, an inelastic deformation section and a broken section. The compressive strength apparently 


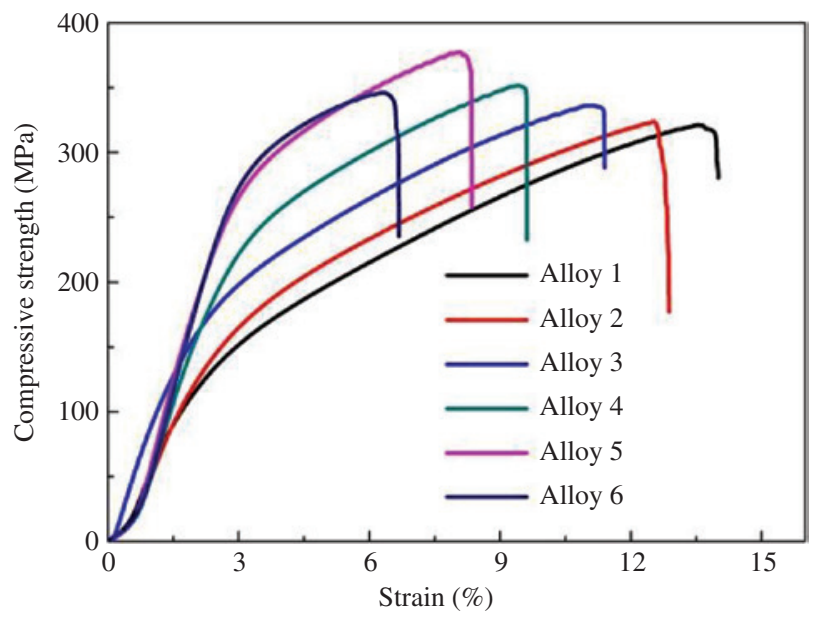

Figure 5: Compressive stress-strain curves of the base Mg alloy (alloy 1) and FAC/Mg alloy degradable composites (alloy 2, alloy 3, alloy 4, alloy 5 and alloy 6).

enhances with the increase of the mass fraction of FAC from 0 to 8 wt. $\%$, after which a slight decrease with the addition of $10 \mathrm{wt} . \%$ FAC. It is worth noting that the addition of FAC into the base $\mathrm{Mg}$ alloy decreases the strain rate of the composites. The maximum value of the compressive strength of the composites is $375 \mathrm{MPa}$, whereas its strain rate downs to $8.17 \%$. The strengthening can be attributed to a combined effect of grain-refined and dispersion strengthening of the $\mathrm{Mg}_{2} \mathrm{Si}$ phase. In addition, the difference in the coefficient of thermal expansion of the FAC and Mg matrix causes large thermal mismatch stress [24]. It would result in an increased dislocation density of the composites, which leads to an increase in compressive strength [25-27]. The higher the mass fraction, the slower the dispersion uniformity of the FAC. Accordingly, it causes local segregation of the FAC, and therefore, the compressive strength decreases [17].

\subsection{Corrosion behavior}

Figure 6 shows the corrosion rate of the composites with different FAC contents in the four periods, which were tested at $25^{\circ} \mathrm{C}$ (Figure $6 \mathrm{a}$ ), $50^{\circ} \mathrm{C}$ (Figure $6 \mathrm{~b}$ ) and $80^{\circ} \mathrm{C}$ (Figure $6 \mathrm{c}$ ) in 3-wt. $\% \mathrm{KCl}$ solution. It can be seen that the temperature has a significant effect on the corrosion rate of the degradable composites. Alloy 6 (10 wt.\% FAC contents) shows a maximum corrosion rate of $5.02 \mathrm{~g} / \mathrm{h}\left(80^{\circ} \mathrm{C}\right), 2.32 \mathrm{~g} / \mathrm{h}\left(50^{\circ} \mathrm{C}\right)$ and $0.75 \mathrm{~g} / \mathrm{h}\left(25^{\circ} \mathrm{C}\right)$, which is three times higher than that
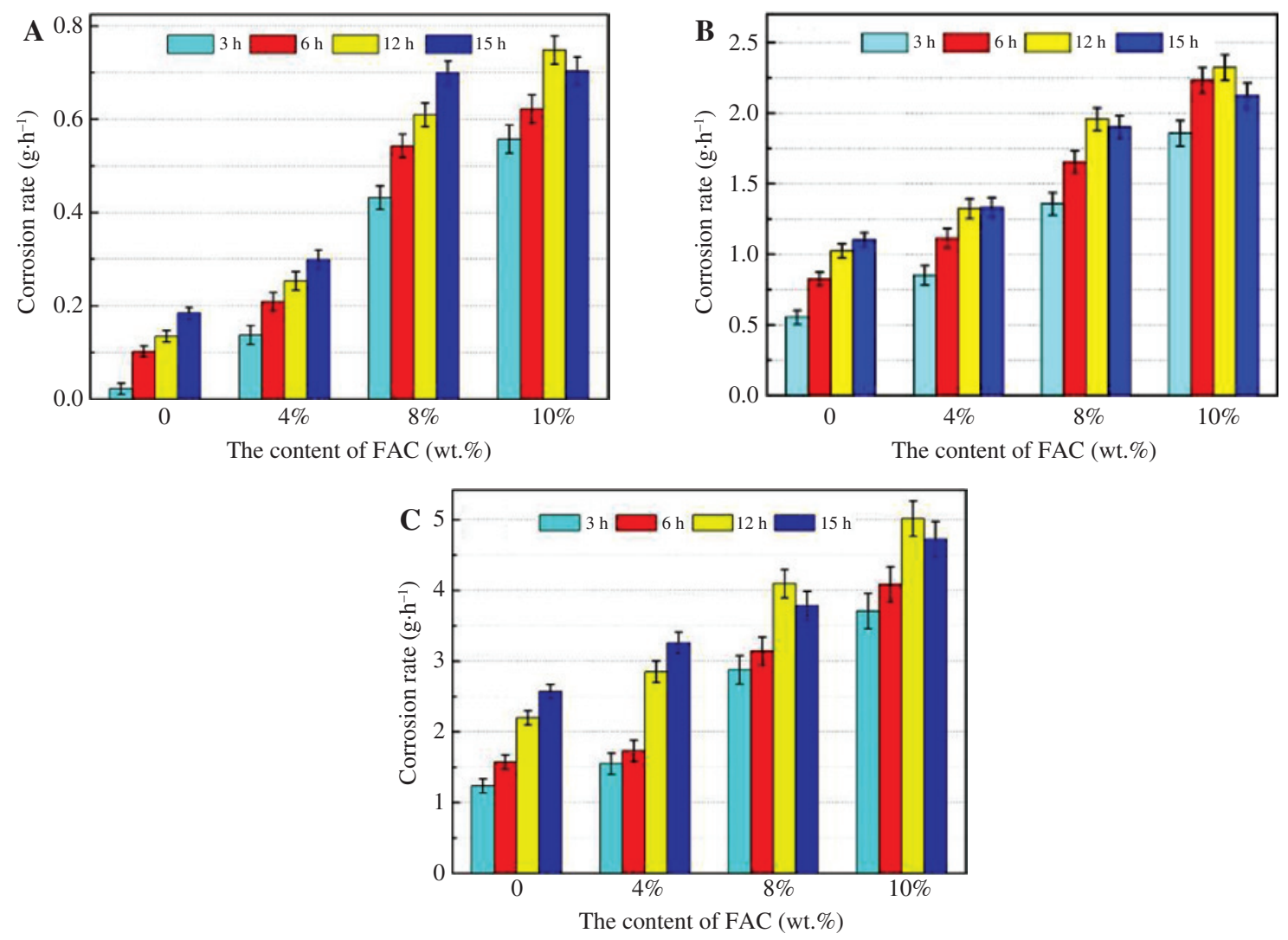

Figure 6: Corrosion rates of the investigated degradable composites in $3 \% \mathrm{KCl}$ at (A) $25^{\circ} \mathrm{C}$, (B) $50^{\circ} \mathrm{C}$ and (C) $80^{\circ} \mathrm{C}$. 


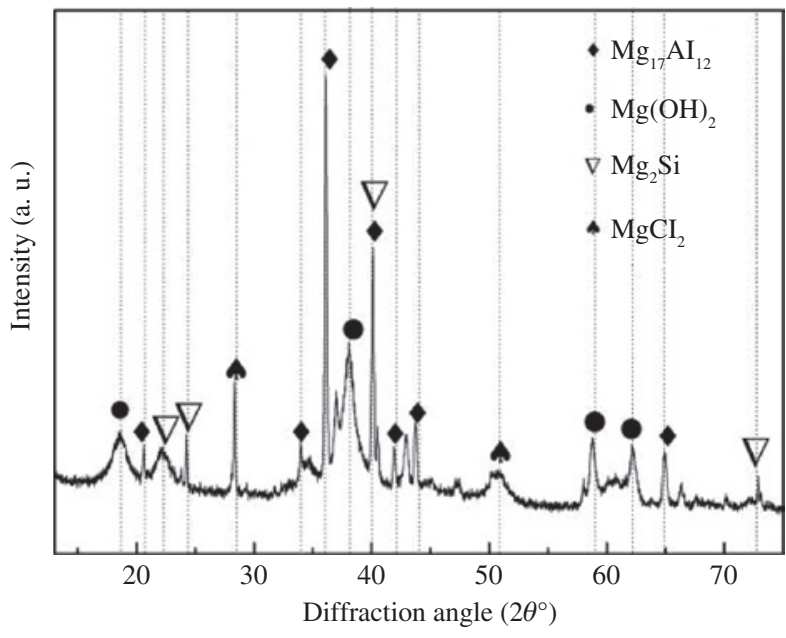

Figure 7: XRD pattern of the degradation product of the $\mathrm{FAC} / \mathrm{Mg}$ alloy degradable composites in $3 \mathrm{wt} . \% \mathrm{KCl}$ solution.

of the base Mg alloy. As the concentration of FAC increases, the corrosion rate gradually increases. The trend can be attributed to the amount of $\mathrm{Mg}_{2} \mathrm{Si}$ or other phases rise. Hence, there are more micro-galvanic corrosion forming in the $\alpha-\mathrm{Mg}$ matrix, $\beta-\mathrm{Mg}_{17} \mathrm{Al}_{12}$ and $\mathrm{Mg}_{2} \mathrm{Si}$ phase, which results in the increase in the corrosion rate of the composites. A similar trend is observed with the time change. While the immersion time is longer than $12 \mathrm{~h}$, the corrosion rates of alloys 5 and 6 slightly decrease, owing to the accumulation of corrosion products on the sample surface.

The standard electrochemical potential of $\mathrm{Mg}(-2.37$ $\mathrm{V})$ is lower than $\mathrm{Al}(-1.66 \mathrm{~V})$ and $\mathrm{Si}(-1.24 \mathrm{~V})$, leading to the extremely excellent chemical activity [28]. When $\mathrm{Mg}$ alloys are in the chloride ions solution, the following electrochemical reactions occur:

$$
\begin{gathered}
\text { Anodic reaction: } \mathrm{Mg} \rightarrow \mathrm{Mg}^{2+}+2 \mathrm{e}^{-} \\
\text {Cathodic reaction: } 2 \mathrm{H}_{2} \mathrm{O}+2 \mathrm{e}^{-} \rightarrow \mathrm{H}_{2} \uparrow+2 \mathrm{OH}^{-} \\
\text {Total reaction: } \mathrm{Mg}+2 \mathrm{H}_{2} \mathrm{O} \rightarrow \mathrm{Mg}(\mathrm{OH})_{2} \downarrow+\mathrm{H}_{2} \uparrow
\end{gathered}
$$

First, the oxide films on the surface layer of the composites can inhibit the aggressive chloride ions penetrating into the alloys. Then, the formation of less resistant Mg hydroxide films on the surface, which is characterized by loose and porous, results in the passageways for the chloride ions. The pitting corrosion initiates in the $\alpha-\mathrm{Mg}$ matrix. Then the corrosion turns into the interior of the composites, and the $\beta-\mathrm{Mg}_{17} \mathrm{Al}_{12}$ and $\mathrm{Mg}_{2} \mathrm{Si}$ phases peel off in the process of corrosion.

Figure 7 shows the XRD pattern of the FAC/Mg alloy degradable composite degradation product in 3-wt. $\% \mathrm{KCl}$ solution. It suggests that the main phases in the degradation product are $\beta-\mathrm{Mg}_{17} \mathrm{Al}_{12}, \mathrm{Mg}(\mathrm{OH})_{2}, \mathrm{Mg}_{2} \mathrm{Si}$ and $\mathrm{MgCl}_{2}$. The analysis result is in accordance with the above theory. Figure 8 shows the micro-morphologies of the corrosion surfaces of the degradable composites at different times in the 3-wt.\% $\mathrm{KCl}$ solution. The corrosion morphologies of the degradable composites have changed from pitting corrosion to total corrosion. Some corrosion holes form on the surface of degradable composites.

Figure 9 shows the potentio-dynamic polarization curves of the degradable composites with different FAC contents in the 3 -wt. $\% \mathrm{KCl}$ solution at $25^{\circ} \mathrm{C}$, and $E_{\text {corr }} I_{\text {corr }}$ and $R_{\mathrm{p}}$ are given in Table 4. It can be observed from the polarization curves that, relatively, the $E_{\text {corr }}$ changes toward negative values with increasing FAC contents. Alloy 1 with 0 wt.\% FAC has the maximum corrosion potential value $(-1.25 \mathrm{~V})$, and alloy 6 with $10 \mathrm{wt} . \% \mathrm{FAC}$ has the minimum corrosion potential value $(-1.43 \mathrm{~V})$, which leads to the conclusion that FACs decrease the corrosion resistance of the composites. The current density $I_{\text {corr }}$ varies with the addition of FAC, with alloy 1 having them lowest minimum value $\left(2.92 \times 10^{-4} \mathrm{~A} / \mathrm{cm}^{2}\right)$ and alloy 6 having the highest value $\left(5.38 \times 10^{-3} \mathrm{~A} / \mathrm{cm}^{2}\right)$, which indicates that corrosion rate increases with the increase in FACs. Similarly, alloys 1 and 6 reveal the maximum $\left(58.36 \Omega / \mathrm{cm}^{2}\right)$ and minimum (3.856 $\left.\Omega / \mathrm{cm}^{2}\right)$ values of $R_{\mathrm{p}}$, respectively. The fractions of $\beta$ and $\mathrm{Mg}_{2}$ Si phases in alloy 6 are the highest, compared
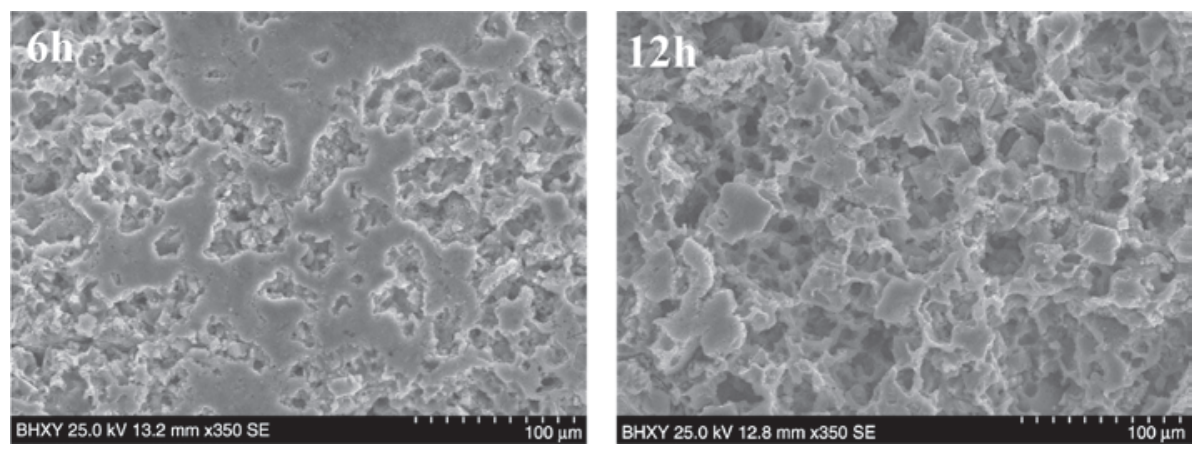

Figure 8: Micro-morphologies of degradable composite at different time in $3 \mathrm{wt} \% \mathrm{KCl}$ solution. 


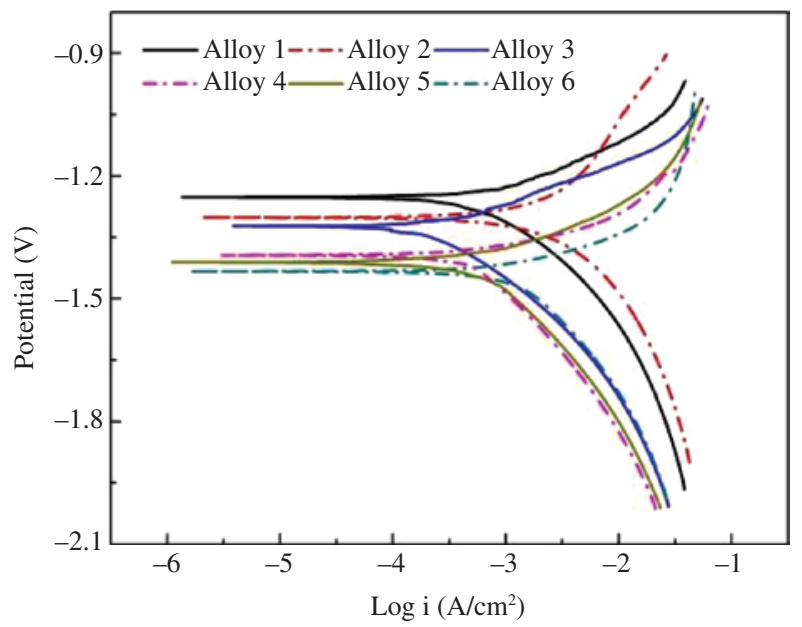

Figure 9: Polarization curves of the investigated degradable composites in $3 \mathrm{wt} . \% \mathrm{KCl}$ at $25^{\circ} \mathrm{C}$.

Table 4: Electrochemical data of the composites with different FAC contents in 3 wt. $\% \mathrm{KCl}$ at $25^{\circ} \mathrm{C}$.

\begin{tabular}{lllr}
\hline Sample & $\boldsymbol{E}_{\text {corr }} / \mathbf{V}$ & $\boldsymbol{I}_{\text {corr }}\left(\mathrm{A} / \mathrm{cm}^{2}\right)$ & $\boldsymbol{R}_{\mathrm{p}}\left(\boldsymbol{\Omega} / \mathrm{cm}^{2}\right)$ \\
\hline Alloy 1 & -1.25 & $2.92 \times 10^{-4}$ & 58.36 \\
Alloy 2 & -1.30 & $6.85 \times 10^{-4}$ & 46.13 \\
Alloy 3 & -1.32 & $9.31 \times 10^{-4}$ & 45.89 \\
Alloy 4 & -1.39 & $1.26 \times 10^{-3}$ & 12.65 \\
Alloy 5 & -1.41 & $2.58 \times 10^{-3}$ & 5.221 \\
Alloy 6 & -1.43 & $5.38 \times 10^{-3}$ & 3.856 \\
\hline
\end{tabular}

with the other composites. Therefore, more $\mathrm{Mg}_{2} \mathrm{Si}$ particles serve as the active galvanic cathode to accelerate the dissolution of $\alpha-\mathrm{Mg}$ matrix. All of the data are consistent with the macro-immersion tests (results shown in Figure 6A, $\mathrm{B}$ and $\mathrm{C}$ ), which demonstrate that alloys 6 and 1 has the lowest and highest corrosion resistance, respectively.

\section{Conclusions}

The excellent compressive strength and rapid degradation rate of these novel $\mathrm{Mg}$ alloy degradable composites reinforced with FACs were successfully developed using stir casting. The main results are as follows:

1. The FAC/Mg alloy degradable composites are mainly composed of $\alpha-\mathrm{Mg}, \beta-\mathrm{Mg}_{17} \mathrm{Al}_{12}, \mathrm{Mg}_{2} \mathrm{Si}$ and $\mathrm{MgO}$ phases. Addition of FAC results in the refinement of the grains, and more $\mathrm{Mg}_{2} \mathrm{Si}$ particles can be found with increasing mass fraction of FACs.

2. The densities of FAC/Mg alloy degradable composites are in the range of $1.8843-2.0526 \mathrm{~g} / \mathrm{cm}^{3}$, which increase with increasing weight percentage of FAC; however, the practical values are higher than the theoretical values owing to the presence of filled FAC by the $\mathrm{Mg}$ matrix and $\mathrm{Mg}_{2} \mathrm{Si}$ compound.

3. The compressive strength of the composites obviously increases compared with the base Mg alloy, with the composites containing $8 \mathrm{wt} . \% \mathrm{FAC}$ having the highest compressive strength of $375 \mathrm{MPa}$ and the compressive strength of the composites containing $10 \mathrm{wt} . \%$ FAC becoming slightly lower.

4. The corrosion rate of the composites increases with the amount of FAC. Alloy 6 shows the highest corrosion rate $(5.02 \mathrm{~g} / \mathrm{h})$ in $3 \mathrm{wt} . \% \mathrm{KCl}$ solution at $80^{\circ} \mathrm{C}$, which is three times higher than that of alloy 1 without FAC. According to the polarization curves, the $E_{\text {corr }}$ changes toward negative values with FAC increase.

Acknowledgments: This work was supported by Key Research and Development Project of Shandong Province of China (No. 2016GGX102041).

\section{References}

[1] Watson DR, Durst DG, Harris JT, Contreras JD. Presented at the CIPC/SPE Gas Technology Symposium, Calgary, Alberta, Canada, 2008, pp. 16-19.

[2] Lian ZH, Zhang Y, Zhao X, Ding SH, Lin TJ. Nat. Gas. Ind. B 2015, 2, 185-191.

[3] Dan T. J. Pet. Technol. 2011, 63, 52-55.

[4] Haghshenas A, Nasr-El-Din HA. J. Nat. Gas. Sci. Eng. 2014, 21, 316-325.

[5] Xu CY, Kang YL, Tang L, Li DQ, Chen F. J. Nat. Gas. Sci. Eng. 2014, 21, 425-432.

[6] Xu Z, Agrawal G, Salinas BJ, Hughes B. Presented at the SPE Annual Technical Conference and Exhibition, Denver, CO, USA, 2011, pp. 1-6.

[7] Xu Z, Agrawal G. US Patent EP20100836533, 2011.

[8] Zhang L, Peng Z, Yu J. Chem. Eng. Oil. Gas 2012, 42, 165-167.

[9] Carrejo N, Wibowo H, Espinoza OR, Gaudette SL. Presented at the SPE Unconventional Resources Conference-Canada, Calgary, Alberta, Canada, 2013.

[10] Pollock TM. Science 2010, 328, 986-987.

[11] Joost WJ. J. Met. 2012, 64, 1032-1038.

[12] Fridlyander IN. Met. Sci. Heat Treat. 2002, 44, 292-297.

[13] Wu Y, Wu K, Nie K, Deng K, Hu X, Wang X, Zheng MY. Mater. Sci. Eng. A 2010, 527, 7873-7877.

[14] Bochenek A, Braszczyńska KN. Mater. Sci. Eng. A 2000, 290, 122-127.

[15] Wang H, Jiang Q, Li X, Wang J, Guan Q, Liang H. Mater. Res. Bull. 2003, 38, 1387-1392.

[16] Su H, Gao W, Feng Z, Lu Z. Mater. Des. 2012, 36, 590-596.

[17] Huang Z, Yu S, Hu M, Shi Y, Li L, Bo G. C.N. Foundation 2015, 12, 406-411.

[18] Nikolaos KK, Charalambos V, Ioannis G. Presented at the World of Coal Ash, ResearchGate, USA, 2005. 
[19] Daoud A, El-Khair MT, Azizl M, Rohatgi P. Compos. Sci. Technol. 2007, 67, 1842-1853.

[20] Rohatgi PK, Guo RQ. Presented at the TMS annual meeting, Warrendale, PA, USA, 1997, 157-168.

[21] ASTM G31-12a, West Conshohocken, PA: ASTM, 2012.

[22] Huang Z, Yu S. J. Alloy Compd. 2011, 509, 311-315.

[23] Li Y, Yu Y, Ren Y. Foun. Eng. 2009, 3, 28-31.
[24] Rohatgi PK, Daoud A, Schultz BF, Puri T. Compos. A 2009, 40, 883-896.

[25] Watson MC, Clyne TW. Acta Metall. Mater. 1992, 40, 131-139.

[26] Arsenault RJ. Mater. Sci. Eng. 1984, 64, 171-181.

[27] Miller WS, Humphreys FJ. Scr. Metall. Mater. 1991, 25, 33-38.

[28] Ghali E, Dietzel W, Kainer KU. J. Mater. Eng. Perform. 2004, 13, 7-23. 